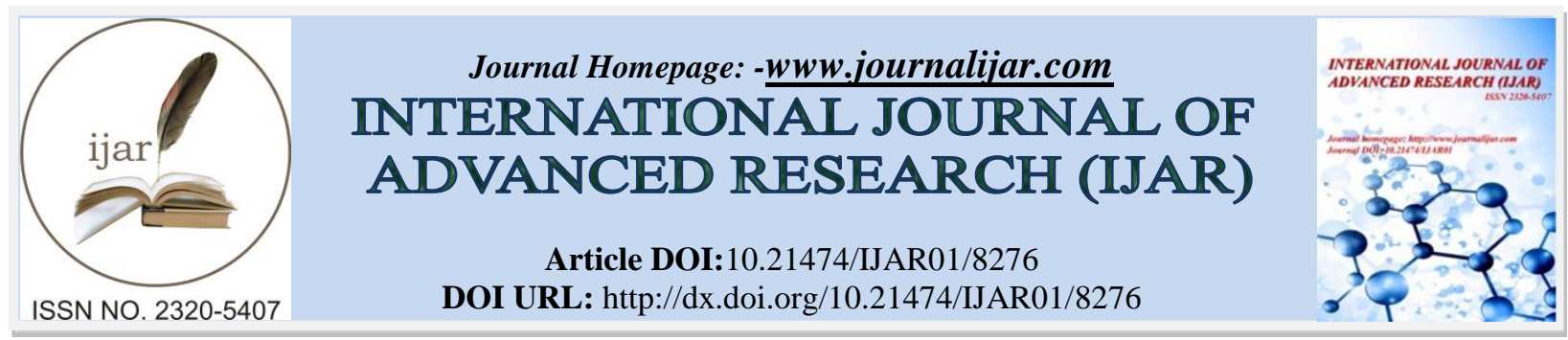

RESEARCH ARTICLE

\title{
POOR FLEXURAL REINFORCEMENT PLACEMENT FACTOR ON THE PERFORMANCE OF CONSTRUCTED DRAINAGE SYSTEM.
}

Kachalla Mohammed.
Civil and Water Resources Engineering Department, University of Maiduguri, N.E. Nigeria.

\section{Manuscript Info}

\section{Manuscript History}

Received: 20 October 2018

Final Accepted: 22 November 2018

Published: December 2018

Key words:-

Workmanship, Drainage, Neutral axis, Reinforced concrete.

\section{Abstract}

Constructional implementation of good structural design that will translate to the require safety and design economy needs good workmanship. Previous structured studies showed that poor workmanship quality would significantly reduce the serviceability reliability and inadequate checks on constructional control resulted in over $90 \%$ of project failure. The statistics are worrisome and challenging. No doubt, flexural reinforcement placement at its designated (tensile or compression) place plays a very important in achieving both the strength requirement and satisfying the serviceability condition. However, a case for haphazardly placed flexural reinforcement for lined-drainage during construction of township road that suffers frequent road embankment failure needs further investigation beyond a structured questioner on the effect of poor workmanship. Hence, this study attempts to access the impact of poor placement of flexural reinforcement at its designated zone primarily due to workmanship error using numerical analysis software. The finding reveals that poor flexural reinforcement placement at its design zone will lead to unnecessary stress built-up and this has farreaching consequences on the performance of the constructed facility. It was found also that a unit change in flexural reinforcement placement position in the tensile zone towards the neutral axis position result in about $3.1 \%$ surge in deformation value.

Copy Right, IJAR, 2017,. All rights reserved.

\section{Introduction:-}

Safety and design economy are the key parameter that governs the design of Reinforced Concrete structures. While satisfying those key parameters, it is of utmost importance that the serviceability requirements are kept to the barest minimum during the service life for a constructed structural unit or part. Many factors influence the behaviour of RC structures, and this includes the flexural reinforcement and its arrangement within the section. There are principally two worrisome cases, and these are either under reinforced or over-reinforced section. In the former case, the neutral axis (N.A.) depth is less than the balanced depth and this will cause the yielding of steel with large deformation. While the later section, the N.A. depth is greater than the balanced depth usually accompanied with brittle failure form because the concrete fails first without warning (Sunil and Sonal, 2017). Undoubtedly, the ductile failure form is preferred because the confining reinforcement increases ductility, hence the large deflections that shows enough warning sign prior to complete failure of the flexural member.

Corresponding Author:-Kachalla Mohammed.

Address:-Civil and Water Resources Engineering Department, University of Maiduguri, N.E. Nigeria. 
Practical implementation of good design that will give the require safety and design economy requires good workmanship; that is the skill and construction quality put into completing a project to a clinical precision. Most often either due to carelessness or other associates factors, the workmanship error might greatly affect the performance of completed project. Figure 1 shows a typical good example for a construction of asphalt pavement with lined drainage. Several studies that were based on structured questioners are found in literature on workmanship related issues during constructions (Ali and Wen, 2011; Mark, 1997; Othman et al., 2014). Those studies result reveals some key elements that affect the workmanship quality, and these includes among others are the skills and competency levels. Additionally, inadequate checks and construction control resulted in over $90 \%$ of project failure. Mark (1997) study result showed that poor workmanship quality would significantly reduce the serviceability reliability by more than an order of magnitude. The statistics is worrisome and challenging. No doubt, flexural reinforcement placement at its designated (tensile or compression) place plays a very important role especially with respect to the associated failure forms as earlier discussed. Evidently as shown using Figure 3, indicates a poorly placed flexural reinforcement and no corrective measures before concreting. Such situations are primarily due to poor workmanship or improper supervision at the construction site, and this cannot be quantified using structured questioners. Structural component failures are envisage under such situations. Hence, this study presents to evaluate the integrity or capacity performance of such system in meeting up its intended function using analytical method. This study outcome will enriched the literature significantly because presently there no available literatures on the effects of poor workmanship in placing flexural reinforcements for drainage system exposed to heavy trucks movement.

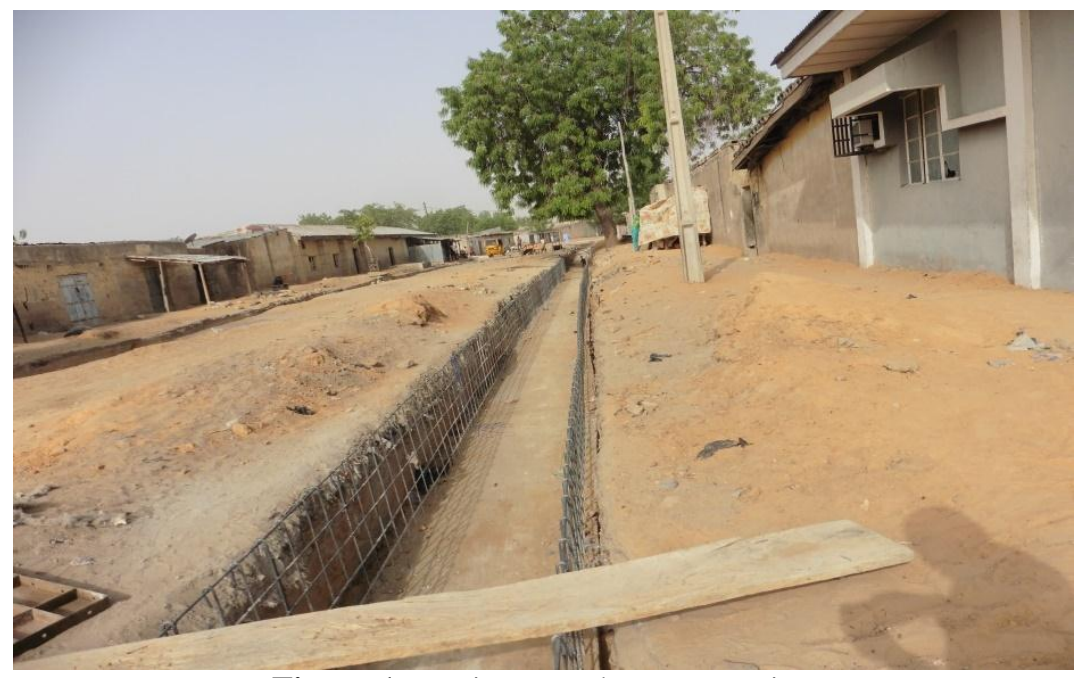

Figure 1:-Drainage under construction

\section{Methodology:-}

The drainage is located at Ngomari Airport Road, off Kano road adjacent to Maiduguri International Airport. The road is a dual carriage-way having side drainage at its both side (Breath, $B=1200 \mathrm{~mm}$ and depth, $D=1300 \mathrm{~mm}$ ). The wall has a thickness value of $150 \mathrm{~mm}$ having a concrete cover value of $30 \mathrm{~mm}$ (Figure 2). The details for the flexural design parameters were obtained from the design engineer at the site, and informed the use of $10 \mathrm{~mm}$ bar both for the longitudinal and transverse directions spaced at $250 \mathrm{~mm}$ centers. The flexural reinforcement placement depth was varied during the numerical analysis in order to obtained the influence of haphazardly placed reinforcement within the wall. Three different locations are considered and these are 30mm away from the N.A., $15 \mathrm{~mm}$ away from the N.A (both within the tensile zone) and $5 \mathrm{~mm}$ after the N.A. point (which falls within the compression face). No attempt was made to verify the suitability for the design parameters given with respect design considerations. However, the analysis length was fixed to $9700 \mathrm{~mm}$. 


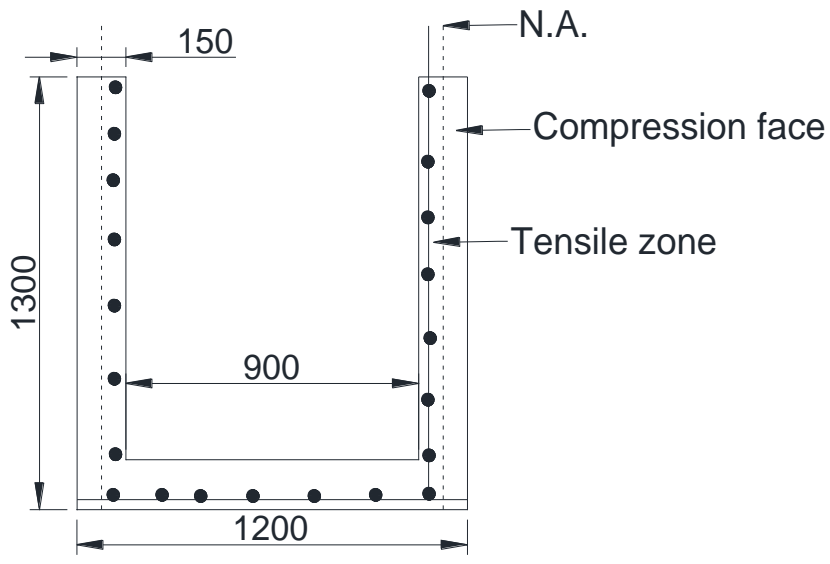

Figure 2:-Channel section.

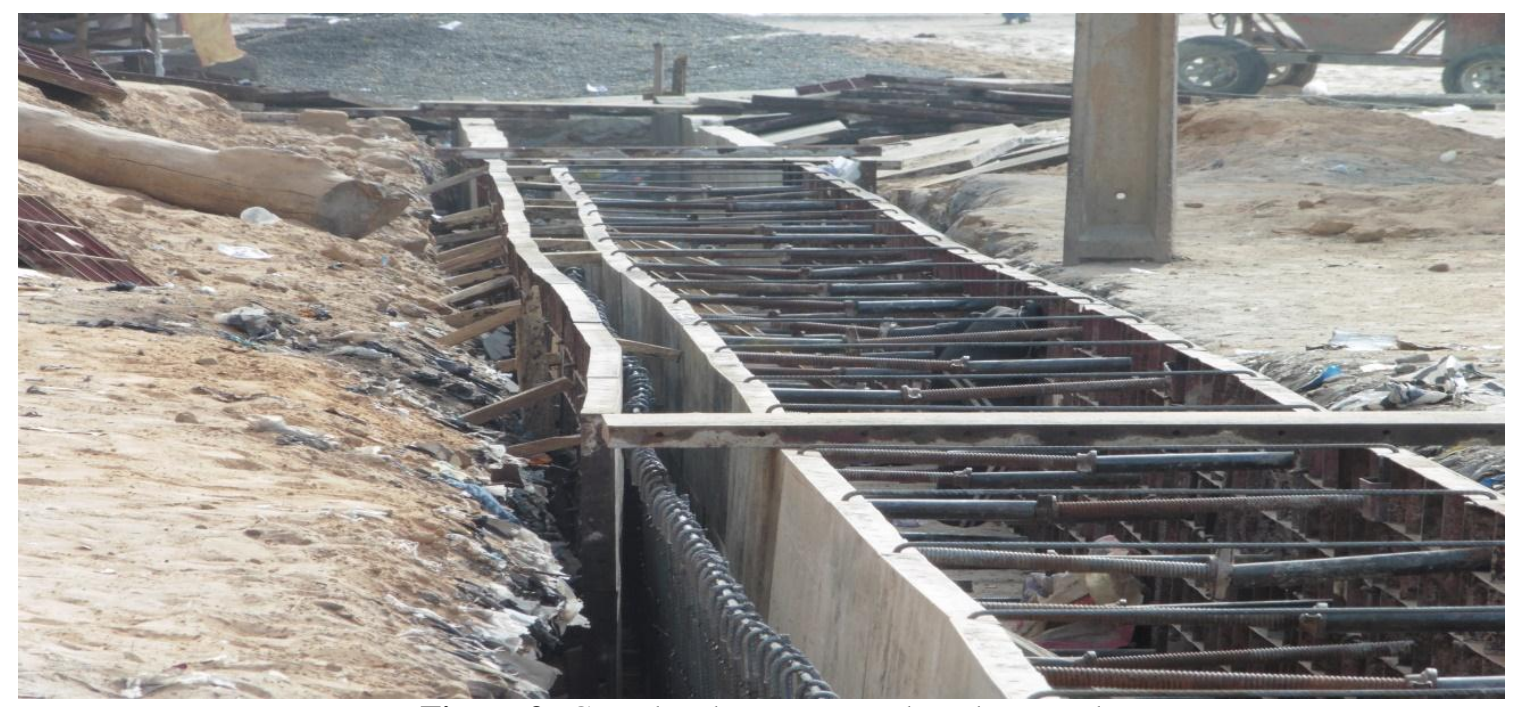

Figure 3:-Completed segment ready to be casted

\section{Numerical Modelling:-}

This study uses ABAQUS application to determine the behavior for $\mathrm{RC}$ drainage. The flexural reinforcement placement position wasintermittently changed from the tensile zone to the compression face with respect to the N.A. position. However, because of section symmetry, only the half of drainage section was subjected to analysis in this study (Figure 4). The finite element model considers both the non-linearity behavior of the concrete and reinforcement medium. The concrete part was deformable solid element while the reinforcement part is also deformable-wire element. The elastic material properties are given using Table 1.

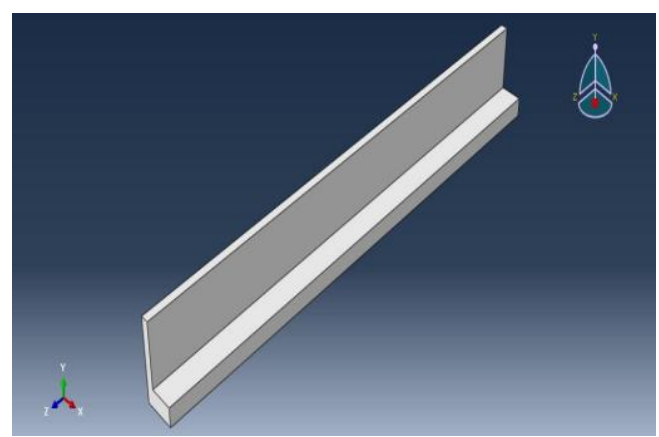

Figure 4:-Typical analysis section 
Table 1:-Materials Elastic Properties

\begin{tabular}{|l|l|l|l|}
\hline Properties & Units & Concrete & Steel \\
\hline Density & $\mathrm{N} / \mathrm{mm}^{3}$ & $2.5 \times 10^{-05}$ & $7.85 \times 10^{-05}$ \\
\hline Elastic Modulus & $\mathrm{N} / \mathrm{mm}^{2}$ & $17 \times 10^{9}$ & $21 \times 10^{9}$ \\
\hline Poisson Ratio & & 0.20 & 0.3 \\
\hline
\end{tabular}

The concrete behavior modelled using the concrete damage plasticity where it assumes failure mechanism through crushing and cracking. This model requires the use of elastic modulus, poisons ratio, the plastic damage parameters and the description of the tensile and compressive behavior. The stress-strain relationship presented in Hamza and Mohannad (2018)was adopted to construct the concrete uniaxial compressive stress-strain curve, and this is by

$$
\begin{gathered}
\delta_{C}=\frac{E_{c} \varepsilon_{c}}{1+\left(R+R_{e}-2\right)\left(\varepsilon_{c} / \varepsilon_{o}\right)-(2 R-1)\left(\varepsilon_{c} / \varepsilon_{o}\right)^{2}+R\left(\varepsilon_{c} / \varepsilon_{o}\right)^{3}} \\
\text { where } R=\frac{R_{e}\left(R_{o}-1\right)}{\left(R_{e}-1\right)^{2}}-R_{e}^{-1} \\
R_{e}=\frac{E_{c}}{E_{0}} \\
E_{o}=\frac{f_{c}}{\varepsilon_{o}}
\end{gathered}
$$

The parameters $R_{o}$ and $R_{e}$ have a value of 4 , while the concrete elastic modulus and its corresponding strain vales are $E_{c}=4700 \sqrt{f_{c}}$ and $\varepsilon_{o}=\left(0.2 f_{c u}+13.06\right) \cdot 10^{-4}$, respectively.

Similarly, the strain-stress relationship for the steel element was in accordance with the method proposed by literature (Hamza and Mohannad, 2018). ABAQUS embedded region function was used to simulate the concrete and reinforcement steel behavior (see Figure 5).
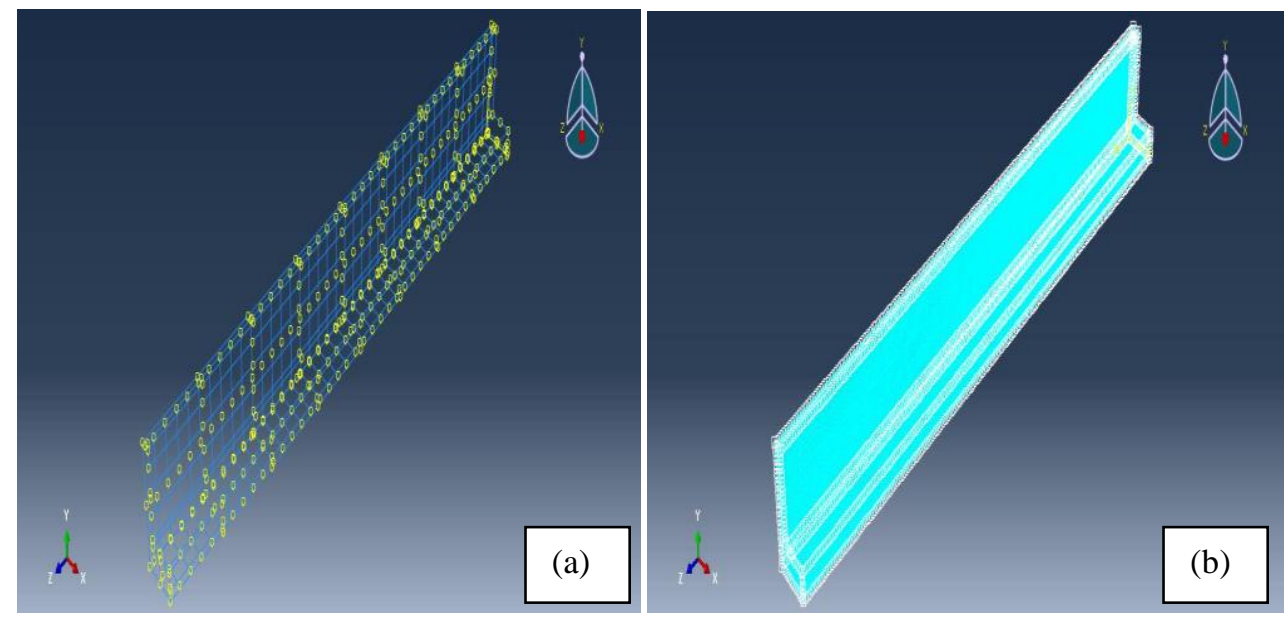

Figure 5:-model part (a) Seeded part with constraint defined, (b) Meshed section

\section{Load and boundary condition:-}

The newly constructed road under this study is open for use to heavy articulated vehicle. Therefore, this study uses a typical tire load value of $18.9 \mathrm{kN}$ and this translates to about $80 \mathrm{kN}$ under the equivalent single axle load (AASHO, 1961). Triangulation loading pattern was adopted and the boundary condition was fixed at the bottom (Figure 6). 


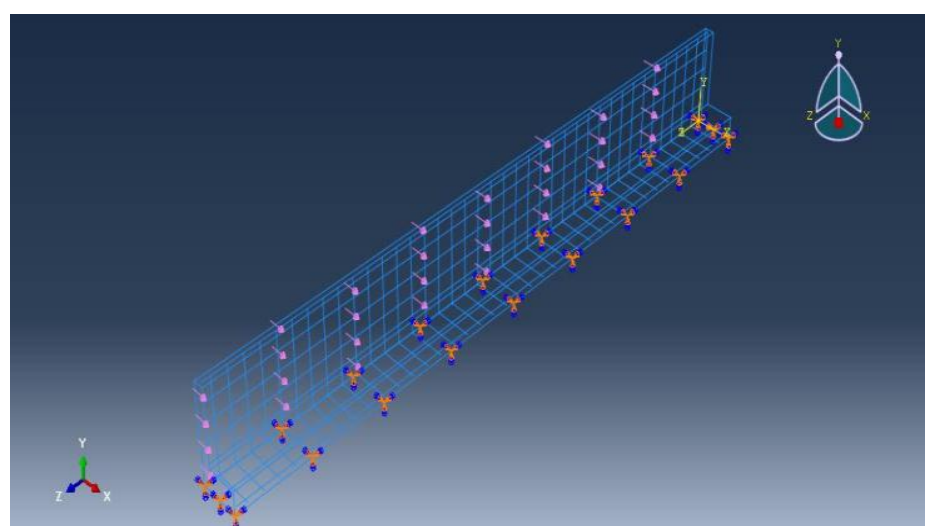

Figure 6:-Load and boundary definition

\section{Result And Discussion:-}

This section presents analysis result for this paper. Figure 7 shows the stress concentration at the stem-base connections with the varying wall-flexural reinforcement placement. In that figure, the stress value significantly increases with assumable wrongful flexural reinforcement placements (i.e $30 \mathrm{~mm}$ to N.A. position - $5 \mathrm{~mm}$ after the N.A. position). The result indicates that improper flexural placement at its designated place will lead to unnecessary stress built-up which have a far reaching consequences on the performance of the constructed drainage facility.

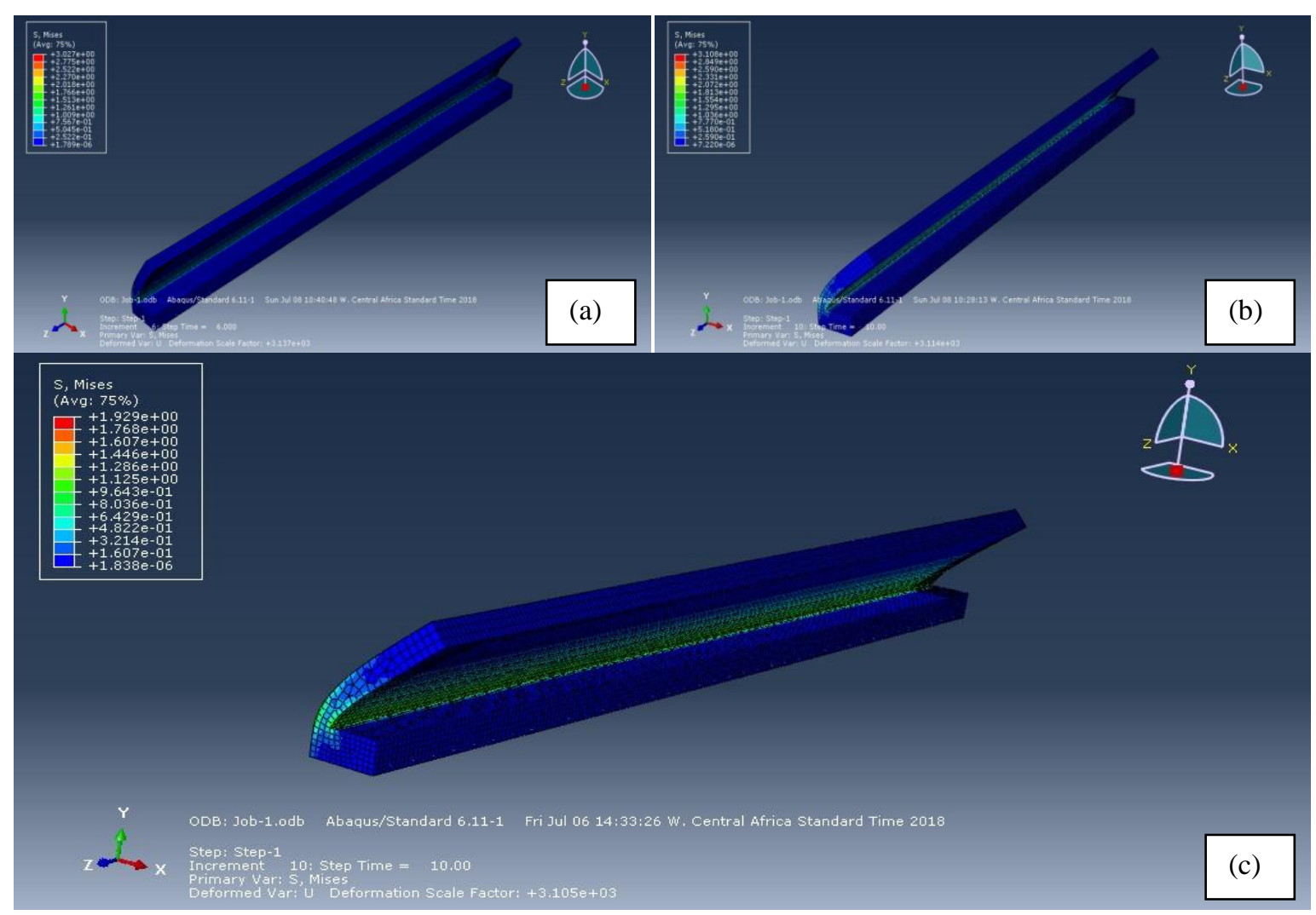

Figure 7:-Von Mises Stress (a) $30 \mathrm{~mm}$ away from the N.A., (b) $15 \mathrm{~mm}$ away from N.A. and (c) $5 \mathrm{~mm}$ after the N.A. 


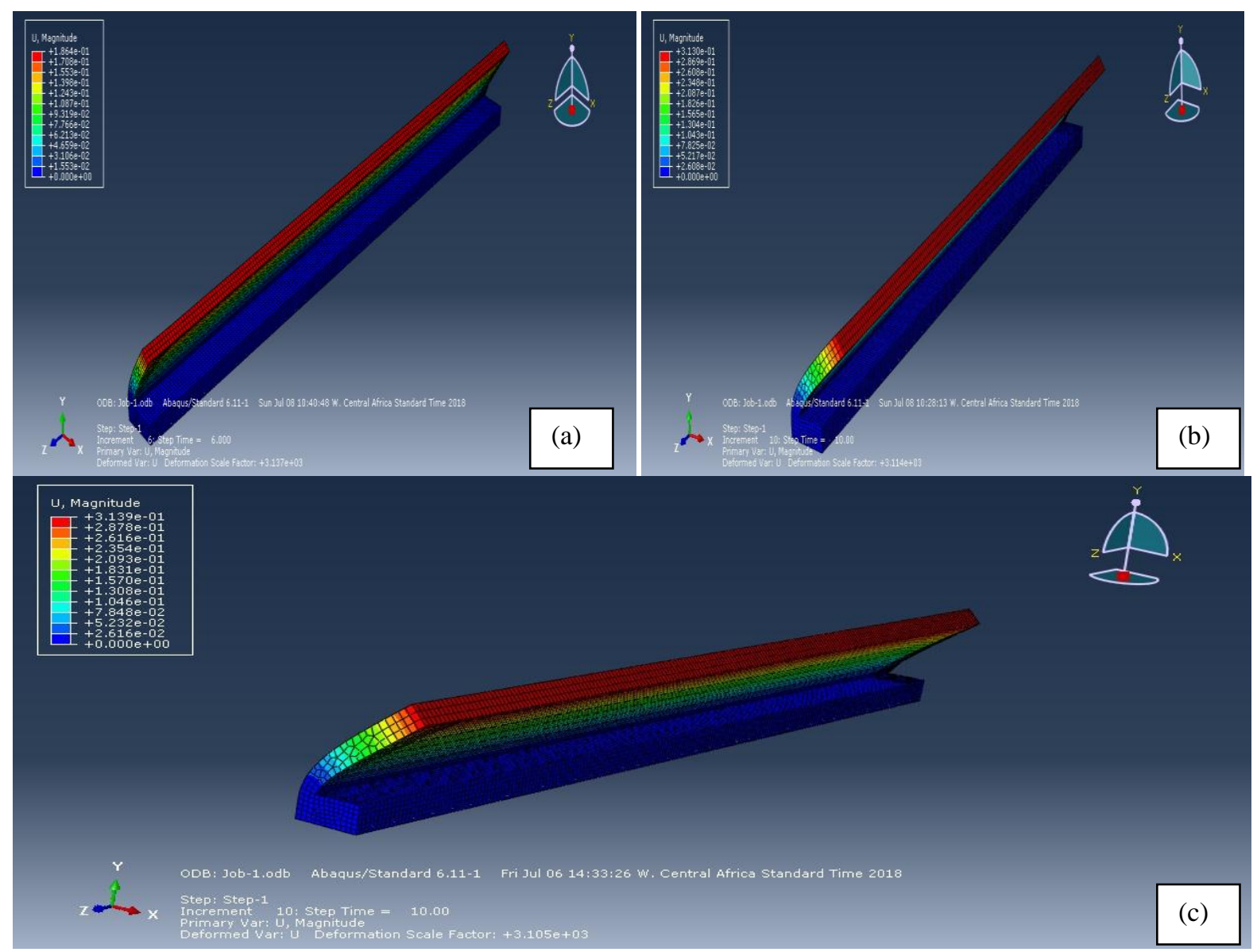

Figure 8:-Displacement behavior (a) $30 \mathrm{~mm}$ away from the N.A., (b) $15 \mathrm{~mm}$ away from N.A. and (c) $5 \mathrm{~mm}$ after the N.A.

The displacement analysis result presented using Figure 8 similarly suggest the behavior previously explained. The farther the flexural reinforcement placement positions the higher deformation value. A unit change in flexural reinforcement position value within the tensile zone towards the N.A. position will result in about $3.1 \%$ surge in deformation value with the same loading arrangement. This principally explains why most the township roaddrainages constructed within that axes fails prematurely. This is true because most of those constructions lack proper implementation of strict construction technology and this will ultimately led to poor workmanship (see Figure 3). Therefore, it is not always sufficient to have good design that reflects the strength requirement capacity while sufficient stiffness to ensure the serviceability (Tahsin and Md. Rahul, 2007), proper construction matters a lot because negligence is the vane of most structural defects occurring at construction sites (Thamilarasu et al., 2017). Statistics have reliability shown that about $90 \%$ of reported buildings failure incidence are closely related workmanship issues (Thamilarasu et al., 2017).

\section{Conclusion:-}

An ongoing lined-drainage construction work for newly asphalted road has been use to access the influence of poor workmanship placement of flexural reinforcement at its rightful position. Numerical modelling simulation for the constructed drainage using ABAQUS revealed that poor flexural reinforcement placement at its design zone will lead to unnecessary stress built-up and this has far-reaching consequences on the performance of the constructed. It was found also that a unit change in flexural reinforcement placement position in the tensile zone towards the neutral axis position result in about $3.1 \%$ surge in deformation value. 


\section{References:-}

1. Ali, A. A., \& Wen, K. H. (2011). Building defects, possible solution for poor construction workmanship. Journal of building performance, 3(23).

2. Hamza, M. S., \&Mohannad, H. A.-S. (2018). Finite Element Model of a Reinforced Concrete Column Strengthened with Steel Jacket. Civil Engineering Journal, 4(5), 10.

3. Mark, G. S. (1997). Concreting workmanship and its inflence on serviceability reliability.ACI Materials Journal, 94(6).

4. American Association of State Highway Officials. (1961). Road test. Ottawa, America.

5. Othman, N. A., Othuman, M. A., \& Md. Sani, N. (2014).Poor workmanship construction of low-cost housing.journal of engineering research and studies, 24(1).

6. Sunil, R., \&Sonal, T. (2017).Effect of size and arrangement of tension reinforcement on flexural behaviour of Reinforced concrete beam.International Journal of Current Engineering Technology, 7(3), 4.

7. Tahsin, R. H., \& Md. Rahul, A. (2007).Deflection estimation of two-way edge-supported slabs.Journal of Civil Engineering (IEB), 35(1), 15.

8. Thamilarasu, V., Rajprasad, J., \& Ram, P. P. T. (2017).A case study on requirements of quality workmanship in construction projects.International Journal of Civil Engineering and Technology, 8(4), 7. 